\title{
Front Matter: Volume 11316
}

, "Front Matter: Volume 11316," Proc. SPIE 11316, Medical Imaging 2020: Image Perception, Observer Performance, and Technology Assessment, 1131601 (1 May 2020); doi: 10.1117/12.2570845

SPIE. Event: SPIE Medical Imaging, 2020, Houston, Texas, United States 


\title{
PROGRESS IN BIOMEDICAL OPTICS AND IMAGING
}

\section{Medical Imaging 2020}

\section{Image Perception, Observer Performance, and Technology Assessment}

\author{
Frank W. Samuelson \\ Sian Taylor-Phillips \\ Editors
}

19-20 February 2020

Houston, Texas, United States

Sponsored by

SPIE

Cooperating Organizations

AAPM-American Association of Physicists in Medicine (United States)

MIPS-Medical Image Perception Society (United States)

SIIM-Society for Imaging Informatics in Medicine (United States)

IFCARS - International Foundation for Computer Assisted Radiology and Surgery (Germany)

WMIS-World Molecular Imaging Society

Published by

SPIE

Volume 11316 
The papers in this volume were part of the technical conference cited on the cover and title page. Papers were selected and subject to review by the editors and conference program committee. Some conference presentations may not be available for publication. Additional papers and presentation recordings may be available online in the SPIE Digital Library at SPIEDigitalLibrary.org.

The papers reflect the work and thoughts of the authors and are published herein as submitted. The publisher is not responsible for the validity of the information or for any outcomes resulting from reliance thereon.

Please use the following format to cite material from these proceedings:

Author(s), "Title of Paper," in Medical Imaging 2020: Image Perception, Observer Performance, and Technology Assessment, edited by Frank W. Samuelson, Sian Taylor-Phillips, Proceedings of SPIE Vol. 11316 (SPIE, Bellingham, WA, 2020) Seven-digit Article CID Number.

ISSN: 1605-7422

ISSN: $2410-9045$ (electronic)

ISBN: 9781510633995

ISBN: 9781510634008 (electronic)

Published by

SPIE

P.O. Box 10, Bellingham, Washington 98227-0010 USA

Telephone +1 3606763290 (Pacific Time) · Fax + 13606471445

SPIE.org

Copyright @ 2020, Society of Photo-Optical Instrumentation Engineers.

Copying of material in this book for internal or personal use, or for the internal or personal use of specific clients, beyond the fair use provisions granted by the U.S. Copyright Law is authorized by SPIE subject to payment of copying fees. The Transactional Reporting Service base fee for this volume is $\$ 21.00$ per article (or portion thereof), which should be paid directly to the Copyright Clearance Center (CCC), 222 Rosewood Drive, Danvers, MA 01923. Payment may also be made electronically through CCC Online at copyright.com. Other copying for republication, resale, advertising or promotion, or any form of systematic or multiple reproduction of any material in this book is prohibited except with permission in writing from the publisher. The CCC fee code is 1605$7422 / 20 / \$ 21.00$.

Printed in the United States of America by Curran Associates, Inc., under license from SPIE.

Publication of record for individual papers is online in the SPIE Digital Library.

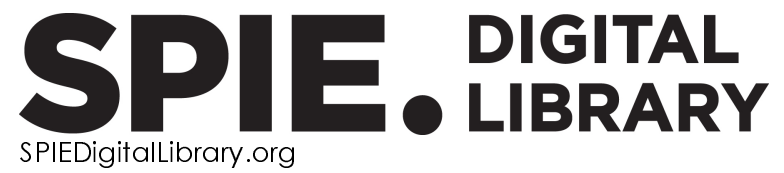

Paper Numbering: Proceedings of SPIE follow an e-First publication model. A unique citation identifier (CID) number is assigned to each article at the time of publication. Utilization of CIDs allows articles to be fully citable as soon as they are published online, and connects the same identifier to all online and print versions of the publication. SPIE uses a seven-digit CID article numbering system structured as follows:

- The first five digits correspond to the SPIE volume number.

- The last two digits indicate publication order within the volume using a Base 36 numbering system employing both numerals and letters. These two-number sets start with $00,01,02,03,04$, 05, 06, 07, 08, 09, OA, OB ... 0Z, followed by 10-1Z, 20-2Z, etc. The CID Number appears on each page of the manuscript. 


\title{
Contents
}

\author{
vii Authors \\ ix Conference Committee \\ xi Awards
}

\section{OBERVER PERFORMANCE EVALUATION}

1131605 Where's WALDO: a potential tool for training radiology residents? [11316-4]

1131607 Understanding digital pathology performance: an eye tracking study [11316-5]

1131608 Effect of time of day on radiology image interpretations [11316-6]

1131609 Blue light filtering glasses and computer vision syndrome: a pilot study [11316-7]

$113160 \mathrm{~A} \quad$ Using "Reader Disagreement Index" as a predictive reviewer performance monitoring tool for timely intervention [11316-8]

MODEL OBSERVERS I

$11316 \mathrm{OB} \quad$ Supervised learning of model observers for assessment of $\mathrm{CT}$ image reconstruction algorithms [11316-9]

$113160 \mathrm{C}$ Learning efficient channels with a dual loss autoencoder [11316-10]

11316 OD Markov-Chain Monte Carlo approximation of the Ideal Observer using generative adversarial networks [11316-11]

11316 OE Deep learning-based model observers that replicate human observers for PET imaging [11316-12]

11316 OF Deep learning based model observer by U-Net [11316-13]

\section{BREAST}

$113160 G$ Sequential reading effects in Dutch screening mammography [11316-14] 
$11316 \mathrm{OH} \quad$ Breast density in Saudi Arabia: intra and inter reader variability in screening mammograms assessed visually using BI-RADS and visual analogue scales [11316-15]

11316 Ol Repeatability profiles towards consistent sensitivity and specificity levels for machine learning on breast DCE-MRI [11316-16]

$113160 \mathrm{~J}$ Investigating the potential of a gist-sensitive computer-aided detection tool [1 1316-17]

ROC METHODOLOGY

11316 OK Multi-reader multi-case analysis of variance software for diagnostic performance comparison of imaging modalities [11316-18]

11316 OL Efficiently calculating ROC curves, AUC, and uncertainty from 2AFC studies with finite samples [11316-19]

$113160 \mathrm{M}$ Simulation of multi-reader multi-case study data with realistic ROC performance characteristics [1 1316-20]

11316 ON Determining Roe and Metz model parameters for simulating multireader multicase confidenceof-disease rating data based on read-data or conjectured Obuchowski-Rockette parameter estimates [11316-21]

TECHNOLOGY ASSESSMENT

$1131600 \quad$ Network output visualization to uncover limitations of deep learning detection of pneumothorax [1 1316-22]

11316 OP Towards a video quality assessment based framework for enhancement of laparoscopic videos [11316-23]

$113160 Q \quad$ Progressively-growing AmbientGANs for learning stochastic object models from imaging measurements [11316-24]

11316 OR Performance assessment of texture reproduction in high-resolution CT [1 1316-25]

11316 OS Supplementing training with data from a shifted distribution for machine learning classifiers: adding more cases may not always help [11316-26]

11316 OT Effect of observer variability and training cases on U-Net segmentation performance [1 1316-27]

\section{MODEL OBSERVERS II}

11316 OU Human observer templates for lesion discrimination tasks [11316-28]

iv 
$113160 \mathrm{~V} \quad$ Foveated model observer to predict human search performance on virtual digital breast tomosynthesis phantoms [11316-29]

11316 oW Learning numerical observers using unsupervised domain adaptation [11316-30]

$113160 X$ Deep learning channelized hotelling observer for multi-vendor DBT system image quality evaluation [11316-31]

11316 OY Convolutional neural network-based anthropomorphic model observer for breast cone-beam CT images [11316-32]

\section{POSTER SESSION}

$113160 Z$ Brain vasculature segmentation based on human perception criteria [11316-33]

1131610 Observer-driven texture analysis in CT imaging [1 1316-34]

1131611 Implementation of an anthropomorphic model observer using convolutional neural network for breast tomosynthesis images [11316-35]

1131612 A performance comparison of convolutional neural network based anthropomorphic model observer and linear model observer for signal-known statistically detection tasks [11316-36]

1131613 Human visual property based grayscale contrast enhancement: phantom based effectiveness assessment [11316-37]

1131614 Perceptual image quality in digital dermoscopy [11316-38]

1131615 Combined global and local information for blind CT image quality assessment via deep learning [11316-39]

1131616 Anthropomorphic ResNet18 for multi-vendor DBT image quality evaluation [1 1316-40]

1131617 Evaluation of convolutional neural networks for search in $1 / \mathbf{f}^{2.8}$ filtered noise and digital breast tomosynthesis phantoms [11316-41]

1131619 Spectral assessment of radiation therapy-induced skin erythema [11316-43] 
Proc. of SPIE Vol. 11316 1131601-6 Downloaded From: https://www.spiedigitallibrary.org/conference-proceedings-of-spie on 26 Apr 2023
Terms of Use: https://www.spiedigitallibrary.org/terms-of-use 


\section{Authors}

Numbers in the index correspond to the last two digits of the seven-digit citation identifier (CID) article numbering system used in Proceedings of SPIE. The first five digits reflect the volume number. Base 36 numbering is employed for the last two digits and indicates the order of articles within the volume. Numbers start with 00, 01, 02, 03, 04, 05, 06, 07, 08, 09, 0A, 0B...0Z, followed by 10-12, 20-2Z, etc.

Abbey, Craig K., OE, OF, OG, OR, OU, OV, 17 Abdlaty, Ramy, 19

Abe, Hiroyuki, Ol

Ahn, Sangtae, OE

Aldossari, Khera, $\mathrm{OH}$

Alfuraih, Abdulrahman, $\mathrm{OH}$

AlMashouq, Taghrid, $\mathrm{OH}$

Almousa, Abeer, $\mathrm{OH}$

AlNaeem, Abdulrahman, $\mathrm{OH}$

Alnasser, Saud, $\mathrm{OH}$

Alomrani, Mona, $\mathrm{OH}$

Aloufi, Areej S., $\mathrm{OH}$

Alshabibi, Abdulaziz S., 08

Alshahrani, Bader, $\mathrm{OH}$

Alzahrani, Iman, $\mathrm{OH}$

Alzimami, Khaled, $\mathrm{OH}$

Anastasio, Mark A., OC, OD, OQ, OW

Astley, Susan, $\mathrm{OH}$

Atwal, Guprit, 07

Autrusseau, Florent, $\mathrm{OZ}$

Avanaki, A., 14

Baek, Jongduk, OY, 11, 12

Bakic, Predrag R., OV, 17

Barufaldi, Bruno, OV, 17

Beghdadi, Azeddine, OP

Beheshtian, Elham, 05

Bhadra, Sayantan, $\mathrm{OQ}$

Bian, Zhaoying, 15

Boone, John M., OU

Bosmans, Hilde, OX, 16

Bourcier, Romain, $\mathrm{OZ}$

Brankov, Jovan G., OF

Brennan, Patrick C., 08, 0J

Broeders, Mireille J. M., OG

Brooks, D., 14

Brooks, Frank J., OQ

Cha, Kenny H., OS

Cheikh, Faouzi Alaya, OP

Chen, Sophia, 00

Chen, Weijie, OM

Chen, Yan, 07

Cockmartin, Lesley, 0X, 16

Crosby, Jennie, 00

Dabrowiecki, Alexander, 09

De Man, Bruno, OE

Doerwald, Lillian, 19

Drukker, Karen, 0 l

Eckstein, Miguel P., OU, OV, 17

Edwin, Bjørn, OP
Ekpo, Ernest U., OJ

Elle, Ole Jakob, OP

Ellis, Ian, 07

Enus, Nicholas, OA

Espig, K., 14

Fan, Fenglei, OE

Fan, Jiahua, 10

Fang, Qiyin, 19

Fei, Zhengyu, 13

Fotinos-Hoyer, Kassel, OA

Fretland, Åsmund Avdem, OP

Fuhrman, Jordan D., OT

Gale, Alastair, 07

Gandomkar, Ziba, 0J

Gang, Grace J., OR

Gao, Qi, 15

Garrett, Zachary, 10

Geertse, Tanya, OG

Giger, Maryellen L., Ol, 00, 0T

Gossmann, Alexej, OS

Granstedt, Jason L., OC

Guillou, Julia, OZ

Halloran, Peter, OT

Han, Minah, OY, 12

Harkness, Elaine F., $\mathrm{OH}$

Hayward, Joseph, 19

$\mathrm{He}$, Shenghua, OW

Heard, Robert, 08

Henschke, Claudia I., OT

Hillis, Stephen L., OK, ON

Jirapatnakul, Artit C., OT

Jonnalagadda, Aditya, 17

Kaaniche, Mounir, OP

Khan, Zohaib Amjad, OP

Kim, Byeongjoon, OY, 12

Kimpe, T., 14

Kinahan, Paul E., OE

Koh, Amanda, 07

Krupinski, Elizabeth A., 05, 09

Kupinski, Matthew A., 10

Lago, Miguel A., OV, 17

Lee, Changwoo, 11

Lewis, Sarah J., OJ

Li, Danyang, 15

$\mathrm{Li}$, Feng, $0 \mathrm{O}$

Li, Hua, OQ, OW

$\mathrm{Li}$, Junyuan, OR

Li, Sui, 15

Li, Tong, OJ 
Liapi, Eleni, OR

Lorente, Iris, OF

LV, Qingwen, 15

Ma, Jianhua, 15

MacMahon, Heber, 00

Madasu, Madhuri, OA

Maidment, Andrew D., OV, 17

Marshall, Nicholas, 0X, 16

Mihai, Raluca, 07

Morales, Robert E., 05

Myers, Kyle J., OU

O'Connor, J. Michael, OA

Ongie, Gregory, OB

Palomar, Rafael, OP

Pan, Xiaochuan, OB

Pelanis, Egidijus, OP

Petrick, Nicholas, OS

Petrov, Dimitar, OX, 16

Pijnappel, RuUd, OG

Reiser, Ingrid S., OB

Roy, Dorina, 07

Sahiner, Berkman, OS

Sahraian, Sadaf, 05

Samuelson, Frank W., OL, OU

Sechopoulos, loannis, OG

Shao, Yibin, OA

Sharma, Manish, OA

Shekter, Dylan H., OL

Shi, Hui, OR

Sidky, Emil Y., OB

Singareddy, Anitha, OA

Smith, Brian J., OK

Snead, David, 07

Stayman, J. Webster, OR

Suleiman, Moayyad E., 08, 0J

Tapia, Kriscia A., 08, 0J

Tavakoli Taba, Seyedamir, 0J

Tetteroo, Eric, OG

Tian, Yi, 13

Trieu, Phuong Dung, 0

Vancoillie, Liesbeth, OX, 16

van der Waal, Danielle, OG

Van Dusen, Amy, Ol

Vieceli, Michael, 이

Villalobos, Alexander, 09

Wangerin, Kristen A., OE

Webster, Michael A., OG

Whitney, Heather M., Ol

Wollenweber, Scott D., OE

Xthona, A., 14

Yang, Yougu, 13

Yankelevitz, David F., OT

Yip, Rowena, OT

Young, J., 14

Yousem, David, 05

Zayed, Mohammed, $\mathrm{OH}$

Zeng, Dong, 15

Zeng, Rongping, OU

Zhan, Henry, 05
Zhou, Wei, 13

Zhou, Weimin, OC, OD, OQ, OW

Zhu, Manman, 15

Zhu, Xiaochen, OM

viii

Proc. of SPIE Vol. $113161131601-8$ 


\section{Conference Committee}

Symposium Chairs

Georgia D. Tourassi, Oak Ridge National Laboratory (United States)

Metin N. Gurcan, Wake Forest Baptist Medical Center (United States)

Conference Chairs

Frank W. Samuelson, U.S. Food and Drug Administration

(United States)

Sian Taylor-Phillips, The University of Warwick (United Kingdom)

Conference Program Committee

Craig K. Abbey, University of California, Santa Barbara (United States) Mark A. Anastasio, Washington University in St. Lovis (United States)

Susan M. Astley, The University of Manchester (United Kingdom)

Jongduk Baek, Yonsei University (Korea, Republic of)

François O. Bochud, Centre Hospitalier Universitaire Vaudois

(Switzerland)

Jovan G. Brankov, Illinois Institute of Technology (United States)

Yan Chen, Loughborough University (United Kingdom)

Brandon D. Gallas, U.S. Food and Drug Administration (United States)

Howard C. Gifford, University of Houston (United States)

Stephen L. Hillis, The University of lowa (United States)

Elizabeth A. Krupinski, Emory University School of Medicine (United States)

Matthew A. Kupinski, College of Optical Sciences, The University of Arizona (United States)

Mark F. McEntee, The University of Sydney (Australia)

Claudia R. Mello-Thoms, University lowa Carver College of Medicine (United States) and University of Pittsburgh (United States)

Robert M. Nishikawa, University of Pittsburgh (United States)

Ljiljana Platiša, Universiteit Gent (Belgium)

Ingrid S. Reiser, The University of Chicago (United States)

Pontus A. Timberg, Skånes Universitetssjukhus, SUS (Sweden)

David L. Wilson, Case Western Reserve University (United States) 


\section{Session Chairs}

1 The Annual Harold L. Kundel Honorary Lecture

Claudia R. Mello-Thoms, University lowa Carver College of Medicine (United States)

Elizabeth A. Krupinski, Emory University School of Medicine (United States)

2 Oberver Performance Evaluation

Mark F. McEntee, The University of Sydney (Ireland)

Craig K. Abbey, University of California, Santa Barbara (United States)

3 Model Observers I

Stephen L. Hillis, The University of lowa (United States)

Howard C. Gifford, University of Houston (United States)

4 Breast

Sian Taylor-Phillips, The University of Warwick (United Kingdom)

François O. Bochud, Centre Hospitalier Universitaire Vaudois (Switzerland)

5 ROC Methodology

Robert M. Nishikawa, University of Pittsburgh (United States)

Craig K. Abbey, University of California, Santa Barbara (United States)

6 Technology Assessment

Mark A. Anastasio, University of Illinois (United States)

Frank W. Samuelson, U.S. Food and Drug Administration (United States)

7 Model Observers II

Matthew A. Kupinski, Wyant College of Optical Sciences (United States)

Jovan G. Brankov, Illinois Institute of Technology (United States) 


\section{Medical Imaging Award Recipients}

\section{Robert F. Wagner Best Student Paper Award}

Robert F. Wagner was an active scientist in the SPIE Medical Imaging meeting, starting with the first meeting in 1972 and continuing throughout his career. He ensured that the $\mathrm{BRH}$, and subsequently the CDRH, was a sponsor for the early and subsequent Medical Imaging meetings, helping to launch and ensure the historical success of the meeting. The Robert F. Wagner All-Conference Best Student Paper Award (established 2014) is acknowledgment of his many important contributions to the Medical Imaging meeting and his many important advances to the field of medical imaging.

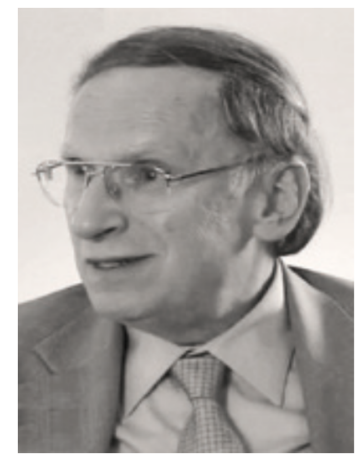

This award is co-sponsored by:

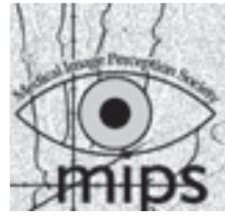

The Medical Image Perception Society

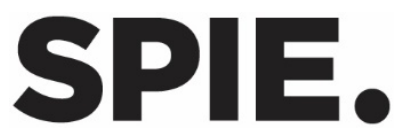

2020 Recipients:

First Place: Multi-body registration for fracture reduction in orthopaedic trauma surgery (11315-14)

R. Han, A. Uneri, P. Wu, R. Vijayan, P. Vagdargi, M. Ketcha, N. Sheth, Johns Hopkins University (United States), S. Vogt, G. Kleinszig, Siemens Healthineers (Germany) G. M. Osgood, John Hopkins Hospital (United States), J. H. Siewerdsen, John Hopkins University (United States)

Second Place: Phase contrast CT enabled three-material decomposition in spectral CT imaging (11312-47)

Xu Ji, Ran Zhang, Ke Li, Guang-Hong Chen, University of Wisconsin School of Medicine and Public Health (United States) 
Proc. of SPIE Vol. 11316 1131601-12

Downloaded From: https://www.spiedigitallibrary.org/conference-proceedings-of-spie on 26 Apr 2023 Terms of Use: https://www.spiedigitallibrary.org/terms-of-use 